\title{
Espacialização da precipitação pluvial por meio de krigagem e cokrigagem
}

\author{
Alexson de Mello Cunha( ${ }^{(1)}$, João Luiz Lani(1), Gerson Rodrigues dos Santos ${ }^{(2)}$, Elpídio Inácio Fernandes Filho(1), \\ Filipe Silveira Trindade ${ }^{(3)}$ e Eliana de Souza ${ }^{(1)}$
}

(1)Universidade Federal de Viçosa (UFV), Departamento de Solos, Avenida Peter Henry Rolfs, s/no, Campus Universitário, CEP $36570-000$ Viçosa, MG. E-mail: alexson.cunha@vta.incra.gov.br, lani@ufv.br, elpidio@ufv.br, elianadsouza@yahoo.com.br(2)UFV, Departamento de Estatística. E-mail: gerson.santos@ufv.br ${ }^{(3)} \mathrm{UFV}$, Departamento de Geografia. E-mail: filipe.strindade@gmail.com

\begin{abstract}
Resumo - O objetivo deste trabalho foi avaliar a cokrigagem ordinária, com dados de altitude e distância do mar, em comparação à krigagem ordinária, na espacialização da precipitação pluvial dos períodos anual, seco e úmido, no Estado do Espírito Santo. Os dados de altitude e distância do mar foram obtidos de pontos de amostragem em grades regulares e irregulares. Foram utilizados dados de 108 postos pluviométricos. A avaliação dos métodos e das variáveis foi realizada com base na validação cruzada, tendo-se considerado os erros dos valores preditos e o ajuste dos modelos de regressão linear para valores observados e preditos. A grade regular para amostragem das covariáveis apresentou melhor acurácia de predição em comparação à grade irregular. A cokrigagem produziu resultados mais acurados do que a krigagem, verificados por pequenas diferenças nos erros médios absolutos, capazes de produzir mapas estatisticamente diferentes. A interpolação por cokrigagem e o uso de grades regulares para amostragem são preferíveis, principalmente se as covariáveis são de fácil obtenção e de baixo custo.
\end{abstract}

Termos para indexação: distribuição da precipitação, geoestatística, linha de costa, predição espacial.

\section{Rainfall spatialization by kriging and cokriging}

\begin{abstract}
The objective of this work was to evaluate the ordinary co-kriging algorithm, using data from elevation and distance from the sea, compared to ordinary kriging, in the rainfall spatialization associated to wet, dry and annual periods, for the state of Espírito Santo, Brazil. Data of altitude and distance from the sea were obtained in sampling sites on regular and irregular grids. Data from 108 rain gauge stations were used. The evaluation of methods and variables based on cross-validation was performed, considering the errors of the predicted values and the fit of linear regression models for observed and predicted values. The regular grid sampling of the covariates showed the best prediction accuracy compared to the irregular grid. Cokriging produced more accurate results than kriging, checked by small differences in mean absolute errors which were able to produce statistically different maps. Cokriging interpolation and use of regular grids for sampling are preferable, mainly if the covariates are easy to obtain and inexpensive.
\end{abstract}

Index terms: precipitation distribution, geostatistic, coastline, spatial prediction.

\section{Introdução}

A estimativa da variabilidade espacial de chuvas é importante para a determinação do potencial agrícola de uma região e identificação de áreas de risco, onde elevados índices de precipitação pluvial podem levar às inundações (Goovaerts, 2000) e a movimentos de massa ao longo de encostas (Porto Junior et al., 2012).

Frequentemente, os dados de precipitação pluvial são obtidos em postos de coleta pontuais, o que gera a necessidade de utilização de métodos de interpolação espacial para o seu mapeamento, entre os quais se destaca a krigagem (Carvalho \& Assad, 2005; Viola et al., 2010). A krigagem ordinária, um método geoestatístico univariado, tem sido muito utilizada por sua eficiência na interpolação de dados pluviométricos (Carvalho \& Assad, 2005; Viola et al., 2010; Carvalho et al., 2012). A extensão multivariada da krigagem, conhecida como cokrigagem, é utilizada quando há correlação espacial cruzada entre a variável primária e uma variável secundária (Isaaks \& Srivastava, 1989). A utilidade da cokrigagem é muitas vezes reforçada, pelo fato de que a variável primária de interesse pode ser subamostrada em relação a outras covariáveis correlacionadas espacialmente (Isaaks \& Srivastava, 1989). Nesse aspecto, a cokrigagem pode ser mais interessante do que a krigagem, em razão da baixa 
densidade de postos pluviométricos existentes nas áreas de interesse, especialmente em áreas montanhosas de difícil instalação e manutenção de equipamentos.

O método de cokrigagem, para fins de espacialização da precipitação pluvial, envolve geralmente variáveis topográficas (Goovaerts, 2000). Estas variáveis têm baixo custo como fonte de informação secundária, se obtidas de modelos digitais de elevação (Goovaerts, 2000). Dessas variáveis, a altitude tem sido mais utilizada como covariável, e estudos têm mostrado melhorias na acurácia da predição de chuvas com sua utilização na cokrigagem (Diodato \& Ceccarelli, 2005; Moral, 2010; Viola et al., 2010).

Conforme Goovaerts (2000), ao se comparar a cokrigagem com dados de elevação como variável secundária com a krigagem, pode-se verificar a superioridade da cokrigagem. Se a correlação entre a precipitação e a altitude aumenta, aumenta também o ganho da cokrigagem em relação à krigagem. Uma correlação fraca pode fornecer resultados muito similares entre krigagem e cokrigagem, conforme verificado por Rocha et al. (2012) ao analisar a influência de uma variável secundária, como função da correlação com a variável primária, para a cokrigagem colocalizada. Para obter resultados mais acurados, Moral (2010) sugere selecionar o mais apropriado algoritmo geostatístico para cada área de estudo. Assim, deve-se verificar também qual a melhor variável secundária, bem como o seu melhor plano de amostragem.

Ainda segundo Goovaerts (2000), outros descritores ambientais devem ser investigados, os quais podem explicar a grande proporção da variabilidade espacial apresentada pela precipitação pluvial. Alguns autores têm levado em conta a influência marítima sobre a precipitação, em áreas costeiras, e sugerido a distância da costa como uma importante variável no ajustamento de modelos de regressão (Johansson \& Chen, 2003). No entanto, diferentemente da altitude, cujos bons resultados como variável auxiliar na estimativa da precipitação pluvial são conhecidos (Diodato \& Ceccarelli, 2005; Viola et al., 2010), para a variável distância da costa há ainda necessidade de avaliar a utilização como auxiliar na cokrigagem.

A configuração da amostragem dos dados é outro fator que interfere no desempenho preditivo da krigagem (Li \& Heap, 2011). A amostragem regular e a aleatória têm sido duas estratégias comumente utilizadas em geostatística. A regular cobre sistematicamente a área de interesse, mas não representa distâncias menores do que o tamanho da grade. A irregular representa as variações a distâncias mais curtas, no entanto, o espalhamento dos pontos no espaço geográfico é menor do que o da grade regular, o que resulta muitas vezes em menor exatidão global (Hengl, 2007). No entanto, Li \& Heap (2011) estudaram diferentes métodos de interpolação e verificaram maior exatidão da predição com o uso de grades irregulares. Para o caso da krigagem ordinária, Englund et al. (1992) verificaram que o padrão da amostragem não foi significativo para determinar o desempenho do interpolador.

O objetivo deste trabalho foi avaliar a cokrigagem ordinária com dados de altitude e distância do mar, em comparação à krigagem ordinária, na espacialização da precipitação pluvial dos períodos anual, seco e úmido, no Estado do Espírito Santo.

\section{Material e Métodos}

As séries de dados de precipitação pluvial, utilizadas neste estudo, foram obtidas da base de dados da Agência Nacional de Águas (Ana), a partir do sistema de informações hidrológicas Hidroweb (Agência Nacional de Águas, 2011) e da base de dados do Instituto Capixaba de Pesquisa, Assistência Técnica e Extensão Rural (Incaper). No total, utilizaram-se dados de 108 postos pluviométricos, dos quais 96 da Ana e 12 do Incaper. Consideraram-se 25 anos de dados, obtidos dos registros do período de 1976 a 2006.

Os pontos de medição da precipitação estão geograficamente distribuídos, de forma irregular, na área de estudo (Figura 1), com 92 postos inseridos no Estado do Espírito Santo e os outros 16 postos nos Estados de Minas Gerais, Rio de Janeiro e Bahia. A inclusão destes postos fora dos limites da região objeto de estudo teve o objetivo de minimizar o efeito de borda no processo de interpolação (Viviani \& Manzato, 2005). Foram utilizados dados das séries de precipitação disponíveis no sítio da Ana (Agência Nacional de Águas, 2011). No entanto, algumas séries mensais apresentavam falhas, que foram preenchidas pelo método da ponderação regional (Bertoni \& Tucci, 2007). Foram selecionados pelo menos três postos vizinhos, com séries de 10 anos de dados. As consistências das séries de dados do Incaper e dos preenchimentos das falhas foram obtidas pelo método da dupla massa (Bertoni \& Tucci, 2007). Para a análise dos interpoladores, as médias mensais de precipitação 
foram obtidas e agrupadas em três períodos: anual, seco (maio a setembro) e úmido (outubro a abril).

Foram utilizadas a altitude e a distância ao mar como variáveis secundárias na cokrigagem. Estas covariáveis foram obtidas em grades regulares, com espaçamento de $5.000 \times 5.000 \mathrm{~m}$, o que gerou 3.014 pontos amostrais para a área. O espaçamento da grade foi escolhido de forma arbitrária, e não se avaliou qual a melhor densidade de pontos. A mesma quantidade de pontos foi utilizada para obtenção das covariáveis em grades irregulares. Obedeceu-se à distância mínima de $1.000 \mathrm{~m}$ entre pontos, para assegurar melhor distribuição. Para cada um desses pontos, foram obtidos os dados de altitude pela ferramenta "extract values to points do ArcGis 10.0" (Environmental Systems Research Institute, Redlands, CA, EUA), a partir de uma imagem SRTM (Shuttle Radar Topography Mission), com resolução de $90 \mathrm{~m}$. Os valores de altitude foram calculados de células adjacentes com valores válidos, tendo-se utilizado interpolação bilinear. As distâncias dos pontos amostrais, em relação ao mar, foram obtidas com a ferramenta Near do Arcgis 10.0 (Environmental Systems Research Institute, Redlands, CA, EUA), com a qual se determinou a distância de cada ponto amostral em relação à linha de costa. Considerou-se como costa a face do polígono do mapa estadual que limita com o oceano Atlântico (Figura 1).

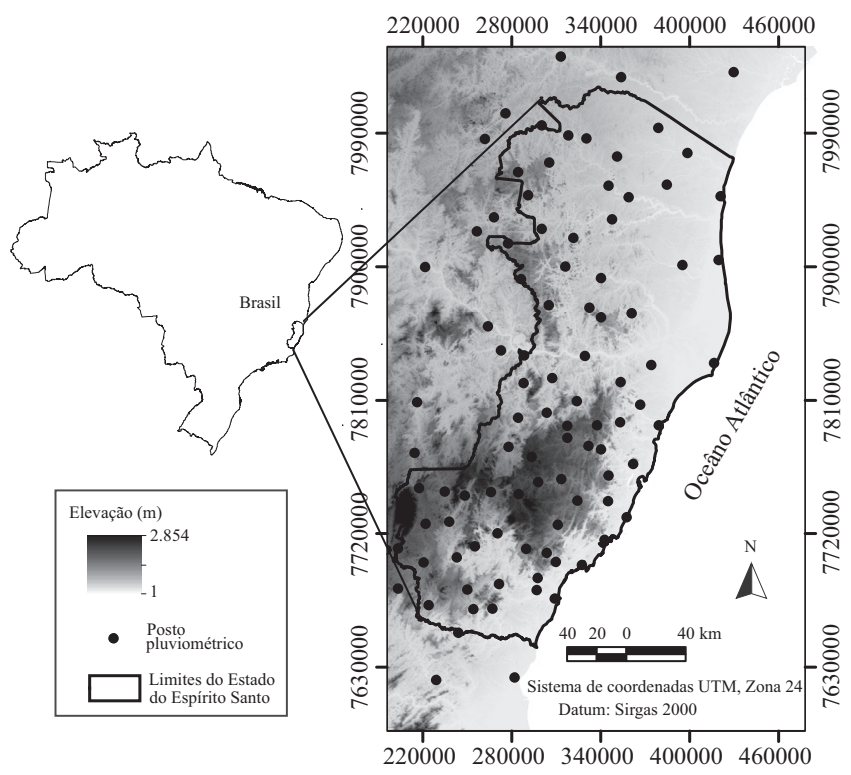

Figura 1. Localização da área de estudo e dos postos pluviométricos utilizados na interpolação, no Estado do Espirito Santo.
Os dados de precipitação pluvial, altitude e distância do mar foram submetidos à análise de correlação de Spearman. Os dados de precipitação pluvial referentes aos três períodos considerados foram submetidos à análise estatística descritiva. Essas análises foram realizadas com o uso do programa $\mathrm{R}$ ( $\mathrm{R}$ Development Core Team, Viena, AT).

O pacote geoR (Ribeiro Junior \& Diggle, 2001), do programa R (R Development Core Team, Viena, AT) foi utilizado e, por meio da análise dos semivariogramas experimentais nas direções $0^{\circ}, 45^{\circ}, 90^{\circ}$ e $135^{\circ}$, foi realizada a verificação de anisotropia dos dados de precipitação pluvial. Para os demais procedimentos, utilizou-se o pacote GeostatisticalAnalyst do programa Arcgis 10.0. (Environmental Systems Research Institute, Redlands, CA, EUA), pelo qual foram realizadas as análises de tendência, o ajuste do semivariograma e a validação cruzada. $\mathrm{O}$ mesmo programa também foi utilizado para realizar a análise geoestatística, pelo fato de este programa permitir a construção de covariogramas cruzados com mais de uma variável secundária.

A krigagem ordinária e a cokrigagem foram realizadas com prévia remoção de tendência dos dados, e foi avaliado e aplicado o modelo que melhor se ajustou aos semivariogramas. Foram realizadas duas cokrigagens, com a utilização de uma covariável apenas, ou seja, cokrigagem precipitação x altitude e cokrigagem precipitação x distância do mar. Avaliou-se também a cokrigagem com três conjuntos de dados, um primário (precipitação) e dois secundários (altitude e distância do mar), para cada período de precipitação pluvial avaliado.

Os parâmetros dos modelos foram estimados automaticamente, com foco nos resultados da validação cruzada. Os raios de busca foram limitados às distâncias correspondentes ao comprimento do maior semieixo da elipse de busca. O número de setor utilizado foi igual a um, o qual foi escolhido conforme o melhor resultado obtido na validação cruzada. O número de setores indica em quantas partes a elipse é dividida para busca de pontos vizinhos.

Mapas dos totais de precipitação, para os três períodos avaliados, e mapas de erro-padrão da predição foram gerados. O mapa de erro-padrão da krigagem, referido como o desvio-padrão da predição para qualquer ponto individual, foi obtido com a finalidade

Pesq. agropec. bras., Brasília, v.48, n.9, p.1179-1191, set. 2013 DOI: 10.1590/S0100-204X2013000900001 
de informar sobre a confiança dos valores interpolados na área de interesse.

As interpolações foram avaliadas por meio do procedimento de validação cruzada (Isaaks \& Srivastava, 1989). Utilizou-se o ajuste do modelo de regressão linear dos valores observados em função dos valores estimados. Quanto mais próximas de 1 e 0 forem as estimativas obtidas para $\beta_{1}$ e $\beta_{0}$, respectivamente, melhor o método de interpolação ou modelo de dependência espacial (Isaaks \& Srivastava, 1989). Utilizaram-se também os valores obtidos para o erro médio absoluto (EMA), em percentagem, e raiz do erro quadrático médio (REQM), os quais são definidos pelas seguintes equações:

$$
\begin{aligned}
& \operatorname{EMA}(\%)=\left(\sum_{\mathrm{i}=1}^{\mathrm{n}} \frac{\left|\hat{\mathrm{z}}_{(\mathrm{si})}-\mathrm{z}_{(\mathrm{si})}\right|}{\mathrm{Z}_{(\mathrm{si})}} \times 100\right) \times \frac{1}{\mathrm{n}} \\
& \operatorname{REQM}=\left[\sum_{\mathrm{i}=1}^{\mathrm{n}}\left(\hat{\mathrm{z}}_{(\mathrm{si})}-\mathrm{z}_{(\mathrm{si})}\right) / \mathrm{n}\right]^{0,5},
\end{aligned}
$$

em que: $z($ si) representa a precipitação observada; ẑ(si), os valores preditos; e $\mathrm{n}$, o número de postos pluviométricos.

A semelhança entre os mapas produzidos foi avaliada pelos valores do índice kappa (Congalton \& Green, 2009), tendo-se considerado como referência o mapa gerado com a utilização do interpolador "inverso de uma potência da distância", dado pela equação:

$$
x p=\frac{\sum_{i=1}^{n}\left(\frac{1}{d_{i}^{m}} \times x i\right)}{\sum_{i=1}^{n}\left(\frac{1}{d_{i}^{m}}\right)},
$$

em que: $x_{p}$ é o atributo interpolado; $x_{i}$ é o valor do atributo do i-ésimo ponto de amostragem; $d_{i}$ é a distância euclidiana entre o i-ésimo ponto de vizinhança e o ponto amostrado; $\mathrm{n}$ é o número de amostras; e m é o expoente da distância euclidiana.

Foram utilizados valores de expoentes das distâncias otimizados pelo programa ArcGis 10.0, em que são avaliados vários valores de expoente, para identificar aquele que produz o menor valor da raiz do erro quadrático médio (REQM). O mínimo de 10 e o máximo de 15 vizinhos mais próximos foram utilizados. Os valores dos expoentes foram: 2,82, para o período úmido; 3,84 , para o período seco; e 3,15, para o período anual. Os valores de precipitação foram agrupados em 10 classes, com base em intervalos geométricos. Verificou-se a significância dos valores dos índices kappa pelo teste estatístico Z (Congalton \& Green, 2009).
Realizou-se uma análise visual dos mapas de precipitação anual, gerados pelos métodos utilizados, e uma comparação dos mapas de erros-padrão da predição da precipitação média anual, para as diferentes macrorregiões do Estado do Espírito Santo (Instituto Jones dos Santos Neves, 2012). Para isso, os mapas gerados para todo o Estado foram segmentados para mostrar as seguintes macrorregiões: Metropolitana, Sul, Noroeste e Norte.

\section{Resultados e Discussão}

A maior variabilidade do regime pluvial entre os postos pluviométricos ocorre na estação seca, conforme o coeficiente de variação apresentado (Tabela 1), o que pode evidenciar diferentes regiões climáticas (Mello \& Silva, 2009). Além deste fato, a alta variabilidade nessa época pode estar relacionada a frentes frias. Segundo Viola et al. (2010), os maiores coeficientes de variação nos meses secos foram encontrados para Minas Gerais. Esses autores associaram a variabilidade dos dados à presença de frentes frias mais intensas na Região Sul, que se enfraquecem à medida que avançam para a direção nordeste, o que indica a existência de correlação entre a precipitação e a altitude.

São vários os fatores que influenciam a distribuição espacial da precipitação, como passagens de frentes frias, fenômenos globais de circulação como o El Niño e La Niña, e o gradiente térmico entre o mar, o continente e o relevo (Mello \& Silva, 2009). Este último pode ser considerado de relevância no Estado do Espírito Santo, em razão dos coeficientes de correlação apresentados, principalmente entre a precipitação do período úmido com a altitude (Tabela 1). Segundo Carvalho \& Assad (2005), índices pluviométricos mais elevados no litoral são relacionados ao relevo concordante (serras que se dispõem paralelamente à linha da costa) e as vertentes a barravento (face em que o vento incide), as quais são mais expostas aos ventos úmidos. Nesse aspecto, conforme Carvalho et al. (2012), o relevo configurase como um importante fator na formação das chuvas orográficas.

O maior coeficiente de correlação linear foi verificado entre a precipitação da estação seca e a distância do mar, o que indica uma forte associação negativa entre as variáveis. A utilização da variável altitude resultou em correlações moderadas e significativas com as precipitações das estações úmida e seca. No entanto, 
ao contrário do comportamento da precipitação na estação úmida, a correlação negativa entre as duas variáveis na estação seca indicou que, nessa época do ano, há redução da precipitação com o aumento da altitude. Assim, as correlações verificadas entre altitude e distância do mar e a precipitação, em pelo menos uma estação do ano, indica o potencial destas nas interpolações por meio de métodos bivariados. Silva \& Lima encontraram baixa correlação entre altitude e precipitação para o Estado do Espírito Santo e, no entanto, obtiveram resultados satisfatórios de predição da precipitação pluvial média mensal.

Os patamares dos semivariogramas direcionais (Figura 2) mostraram-se aproximadamente iguais aos valores das variâncias dos dados (Tabela 1). Uma expressiva similaridade, na região de influência da dependência espacial dos semivariogramas experimentais direcionais, foi verificada apenas quanto à precipitação na estação úmida (Figura $2 \mathrm{~A}$ ). Nesse caso, conforme Carvalho \& Assad (2005), os padrões de dependência espacial podem ser considerados idênticos nas direções $0^{\circ}, 45^{\circ}, 90^{\circ}$ e $135^{\circ}$. Com base nestes comportamentos, é possível avaliar que o modelo isotrópico é suficiente para descrever a estrutura da continuidade espacial da precipitação da estação úmida. Os semivariogramas direcionais dos períodos seco e anual apresentaram comportamento diferenciado da continuidade espacial da precipitação, especialmente nas regiões mais próximas de atingir o patamar (Figura 2 B e 2 C), o que é um indicativo da presença de anisotropia, em que a variabilidade é dependente da direção (Goovaerts, 2000).

No período seco e anual, a anisotropia encontrada foi a do tipo combinada, que é a mais comumente presente em variáveis ambientais (Camargo et al., 2004). Este tipo de anisotropia combina a anisotropia geométrica, refletida pelo mesmo patamar e diferentes alcances com a anisotropia zonal, em que os semivariogramas direcionais apresentam os mesmos alcances e diferentes patamares (Camargo et al., 2004). Nesses dois períodos, os semivariogramas direcionais das precipitações apresentaram comportamentos semelhantes entre si, com distâncias mais curtas entre os pares de pontos (Figura 2). Como, na prática, a estimação dos semivariogramas experimentais é realizada com mais precisão para distâncias próximas da origem (Carvalho et al. 2009), e estes não indicaram acentuada anisotropia para a variável primária, a análise geostatística foi realizada, tendo-se admitido uma distribuição isotrópica. A condição de isotropia para os dados de precipitação foram então assumidas para simplificação de procedimentos, tanto para a construção dos semivariogramas quanto para a dos covariogramas cruzados, conforme as análises direcionais realizadas. Segundo Carvalho et al. (2009), diferenças de altitude podem influenciar a variografia dos dados de precipitação. Nesse aspecto, o relevo do Espírito Santo, com grandes mudanças de altitude a curtas distâncias do litoral, apresenta-se como um provável fator a influenciar a dependência espacial da precipitação nas diferentes direções. No entanto, a causa da anisotropia não é conhecida (Krishna Murthy \& Abbaiah, 2007).

Os modelos de semivariograma e covariograma que melhor se ajustaram aos dados de precipitação e das covariáveis foram o exponencial e o esférico (Tabela 2). No caso da krigagem ordinária, o modelo esférico se mostrou mais ajustado aos dados de precipitação no período seco e anual. Na krigagem ordinária dos dados do período úmido e para os covariogramas cruzados, o modelo exponencial foi o que melhor se ajustou. Em um estudo semelhante,

Tabela 1. Estatística descritiva dos dados de precipitação pluvial média dos períodos úmido, seco e anual, dados de altitude e de distância do mar e coeficientes de correlação de Spearman, no Estado do Espírito Santo.

\begin{tabular}{|c|c|c|c|c|c|c|c|c|c|}
\hline \multirow[t]{2}{*}{ Período $^{(1)}$} & \multirow{2}{*}{$\begin{array}{l}\text { Precipitação } \\
(\mathrm{mm})\end{array}$} & \multirow{2}{*}{$\begin{array}{l}\mathrm{CV} \\
(\%)\end{array}$} & \multirow[t]{2}{*}{$\mathrm{s}^{2}$} & \multirow[t]{2}{*}{ Mínimo } & \multirow[t]{2}{*}{ Máximo } & \multirow[t]{2}{*}{$\mathrm{S}$} & \multirow[t]{2}{*}{$\mathrm{K}$} & \multicolumn{2}{|c|}{ Coeficiente de correlação } \\
\hline & & & & & & & & Altitude & Distância \\
\hline Úmido & $1.016,0$ & 15,0 & 23,28 & 644,40 & $1.450,8$ & 0,30 & $-0,10$ & $0,404 * *$ & $-0,003$ \\
\hline Seco & 216,7 & 38,9 & 7,10 & 83,29 & 447,8 & 0,70 & $-0,38$ & $-0,398 * *$ & $-0,780^{* *}$ \\
\hline Anual & $1.232,6$ & 16,1 & 39,45 & 812,90 & $1.851,9$ & 0,46 & 0,08 & 0,174 & $-0,347^{* *}$ \\
\hline \multicolumn{10}{|l|}{ Covariável } \\
\hline Altitude (m) & 261,1 & 104,7 & 74,73 & 4,00 & $1.041,0$ & 1,13 & 0,08 & & $0,599 * *$ \\
\hline Distância (km) & 68,8 & 65,7 & 2,04 & 0,08 & 190,71 & 0,34 & $-0,64$ & & \\
\hline
\end{tabular}

${ }^{(1)}$ Período para a análise dos interpoladores: Anual; seco, de maio a setembro; e úmido, de outubro a abril. CV, coeficiente de variação; s², variância; S, assimetria; $\mathrm{K}$, curtose. **Probabilidade a $1 \%$. 

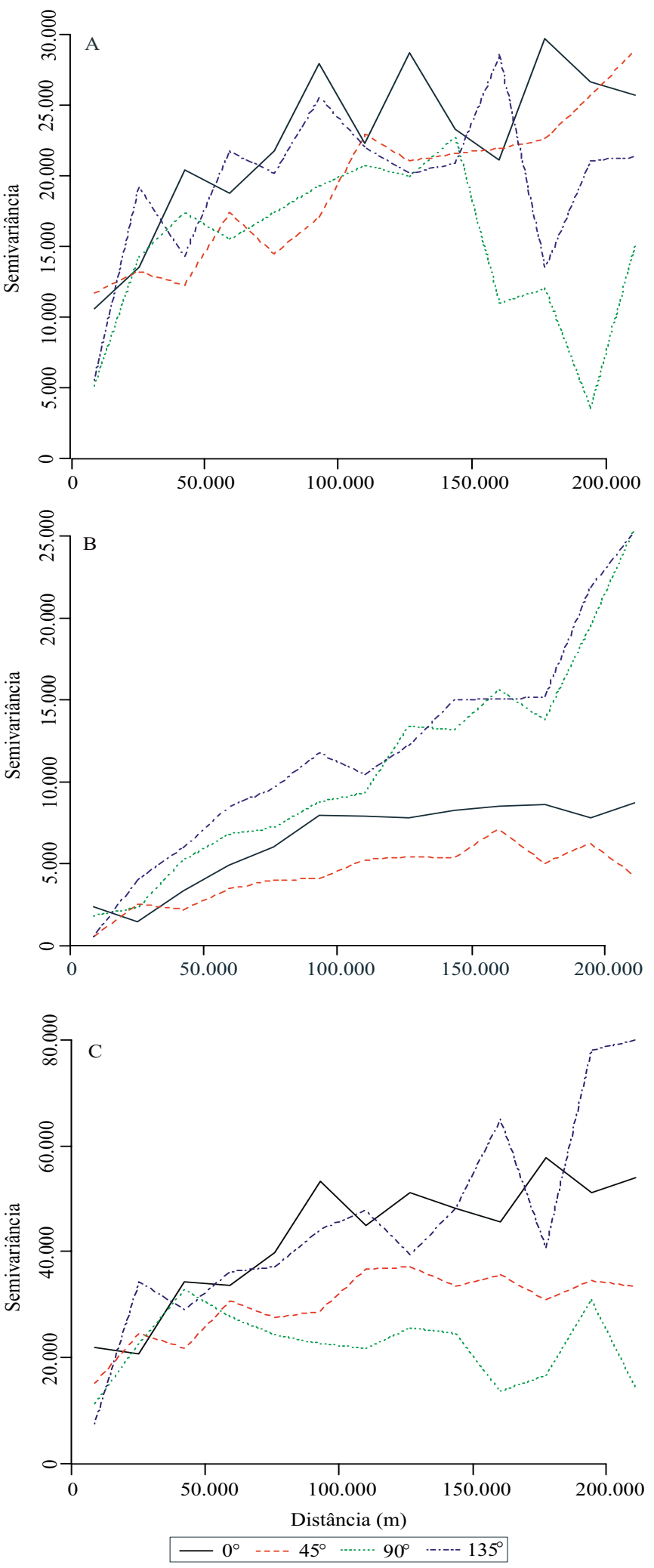

Figura 2. Semivariogramas experimentais para os dados de precipitação dos períodos úmido (A), seco (B) e anual (C), em quatro direções $\left(0^{\circ}, 45^{\circ}, 90^{\circ}\right.$ e $\left.135^{\circ}\right)$. porém com objetivo de espacializar a precipitação pluvial mensal média do Estado do Espírito Santo, por cokrigagem, Silva \& Lima (2011) obtiveram melhor ajuste com o modelo esférico. Na mesma área, Castro (2008) obteve para a precipitação média anual um melhor ajuste com a utilização do modelo linear. Nesse sentido, os resultados deste e de outros trabalhos (Castro, 2008; Silva \& Lima, 2011), para a área de estudo, são indicativos de que o modelo mais adequado para a interpolação de dados de precipitação, por meio de método geoestatístico, pode depender de vários fatores relacionados aos conjuntos de dados como quantidade de postos, tempo considerado na série histórica, períodos do ano, entre outros.

Os alcances apresentados nos semivariogramas para a precipitação anual (Tabela 2) foram menores do que aqueles encontrados por Castro (2008) e Silva \& Lima (2011) para as precipitações médias mensais. No entanto, os resultados encontrados por aqueles autores foram mais próximos aos dos períodos seco e úmido do presente trabalho. Conforme Carvalho et al., (2012), o alcance significa que os pontos localizados numa área, com raio menor ou igual ao valor deste parâmetro, apresentam precipitações semelhantes e estão correlacionados entre si, e que valores não medidos nessa área podem ser estimados com maior precisão. Em geral, independentemente do período considerado, os alcances obtidos nos covariogramas apresentaram média de $76,8 \mathrm{~km}$, ou seja, mais de duas vezes o alcance verificado no semivariograma gerado com os dados de precipitação anual. Apesar do menor alcance, o semivariograma da precipitação anual revelou a mais elevada dependência espacial, indicada pelos valores de efeito pepita e variância estrutural.

$\mathrm{Na}$ validação cruzada para a interpolação dos dados de precipitação anual, os métodos de krigagem ordinária e cokrigagem ordinária produziram resultados comparáveis de erros dos valores preditos, parâmetros de regressão e coeficiente de correlação dos valores observados versus valores preditos (Tabela 3). Entre os dois métodos estocásticos utilizados, a cokrigagem com a altitude produziu o valor mais baixo de REQM, um dos menores erros médios absolutos (EMA) e o mais elevado $\mathrm{R}^{2}$. Os erros absolutos médios dos valores preditos, abaixo de $10 \%$, foram em geral semelhantes aos encontrados por Castro (2008) ao interpolar a precipitação média anual para a mesma área de estudo, 
assim como os resultados da krigagem e cokrigagem com os dados de altitude e de distância do mar.
$\mathrm{Na}$ avaliação das grades regulares e irregulares para obtenção das covariáveis, com vistas à utilização da

Tabela 2. Modelos e parâmetros de semivariogramas e covariogramas cruzados, para a espacialização dos dados de precipitação pluvial média dos períodos úmido, seco e anual, no Estado do Espírito Santo.

\begin{tabular}{|c|c|c|c|c|c|}
\hline Período $^{(1)}$ & Semivariograma / covariograma & Modelo & Efeito pepita - $\mathrm{C}_{0}$ & Variância estrutural - $\mathrm{C}_{1}$ & $\begin{array}{c}\begin{array}{c}\text { Alcance a } \\
(\mathrm{km})\end{array} \\
\end{array}$ \\
\hline \multirow[t]{3}{*}{ Úmido } & Precipitação (P) & Exponencial & 928 & 19.677 & 75 \\
\hline & P x Altitude & Exponencial & & 19.044 & 94 \\
\hline & P x Distância do mar & Exponencial & & -282 & 75 \\
\hline \multirow[t]{3}{*}{ Seco } & Precipitação (P) & Esférico & 600 & 3.055 & 75 \\
\hline & P x Altitude & Exponencial & & 610 & 68 \\
\hline & P x Distância do mar & Exponencial & & -598 & 74 \\
\hline \multirow[t]{3}{*}{$\overline{\text { Anual }}$} & Precipitação (P) & Exponencial & 0 & 27.022 & 30 \\
\hline & P x Altitude & Exponencial & & 25.248 & 75 \\
\hline & P x Dist ância do mar & Exponencial & & 1.173 & 75 \\
\hline
\end{tabular}

${ }^{(1)}$ Período para a análise dos interpoladores: anual; seco, de maio a setembro; e úmido, de outubro a abril.

Tabela 3. Estimativas dos parâmetros da validação cruzada para os semivariogramas ajustados aos dados de precipitação dos períodos úmido, seco e anual, por meio de krigagem ordinária e cokrigagem.

\begin{tabular}{|c|c|c|c|c|c|c|c|}
\hline Krigagem & Semivariograma & Grade & $\begin{array}{c}\text { EMA } \\
(\%)\end{array}$ & $\begin{array}{c}\text { REQM } \\
(\mathrm{mm})\end{array}$ & $\mathrm{R}^{2}$ & $\hat{\beta}_{0}$ & $\hat{\beta}_{1}$ \\
\hline \multicolumn{8}{|c|}{ Período úmido } \\
\hline $\mathrm{KO}$ & Exponencial & & 8,16 & 104,50 & 0,53 & 519,3 & 0,4907 \\
\hline CKA & Exponencial & Regular & 7,68 & 98,4 & 0,58 & 445,1 & 0,581 \\
\hline CKA & Exponencial & Irregular & 7,99 & 103,2 & 0,54 & 497,2 & 0,513 \\
\hline CKD & Exponencial & Regular & 8,13 & 104,3 & 0,535 & 518,0 & 0,498 \\
\hline CKD & Exponencial & Irregular & 8,18 & 104,9 & 0,535 & 522,9 & 0,494 \\
\hline CKAD & Exponencial & Regular & 7,67 & 98,53 & 0,58 & 451,2 & 0,554 \\
\hline CKAD & Exponencial & Irregular. & 8,39 & 107,5 & 0,50 & 548,8 & 0,460 \\
\hline \multicolumn{8}{|c|}{ Período seco } \\
\hline $\mathrm{KO}$ & Esférico & & 12,33 & 38,76 & 0,77 & 19,26 & 0,897 \\
\hline CKA & Exponencial & Regular & 12,05 & 38,33 & 0,78 & 20,74 & 0,891 \\
\hline CKA & Exponencial & Irregular & 12,07 & 38,23 & 0,78 & 21,09 & 0,889 \\
\hline CKD & Exponencial & Regular & 12,44 & 38,68 & 0,78 & 23,15 & 0,882 \\
\hline CKD & Exponencial & Irregular & 12,37 & 38,88 & 0,77 & 20,45 & 0,892 \\
\hline CKAD & Exponencial & Regular & 11,92 & 37,70 & 0,79 & 20,27 & 0,893 \\
\hline CKAD & Exponencial & Irregular & 12,22 & 38,36 & 0,78 & 16,37 & 0,910 \\
\hline \multicolumn{8}{|c|}{ Período anual } \\
\hline $\mathrm{KO}$ & Esférico & & 8,25 & 135,5 & 0,53 & 527,0 & 0,580 \\
\hline CKA & Exponencial & Regular & 7,62 & 124,1 & 0,617 & 480,1 & 0,606 \\
\hline CKA & Exponencial & Irregular & 8,11 & 132,9 & 0,54 & 447,2 & 0,636 \\
\hline CKD & Exponencial & Regular & 8,32 & 135,4 & 0,51 & 452,7 & 0,636 \\
\hline CKD & Exponencial & Irregular & 8,28 & 134,9 & 0,51 & 448,0 & 0,640 \\
\hline CKAD & Exponencial & Regular & 7,60 & 123,6 & 0,61 & 446,6 & 0,633 \\
\hline CKAD & Exponencial & Irregular & 8,06 & 132,5 & 0,54 & 444,2 & 0,638 \\
\hline
\end{tabular}

KO, krigagem ordinária; CKA, cokrigagem com altitude; CKD, cokrigagem com distância do mar; CKAD, cokrigagem com altitude e distância do mar; EMA, erro médio absoluto; REQM, raiz do erro quadrático médio; $\mathrm{R}^{2}$, coeficiente de determinação entre valores preditos e observados. Período seco, de maio a setembro; e úmido, de outubro a abril. 
cokrigagem, verificou-se que as grades regulares para os dados de altitude apresentaram, em geral, maior eficácia na predição espacial da precipitação média anual (Tabela 3 ).

No período úmido, os resultados da validação cruzada da cokrigagem e da krigagem mostraram que os menores valores de REQM, maiores coeficientes de determinação $\left(\mathrm{R}^{2}=0,58\right)$ e melhores ajustes dos parâmetros das regressões foram obtidos para cokrigagem com altitude e cokrigagem com altitude mais distância do mar. Estes resultados evidenciam uma melhor estimativa da precipitação da estação úmida por meio da cokrigagem com a presença da covariável altitude, em comparação às estimativas apresentadas pela krigagem ordinária.

$\mathrm{Na}$ comparação entre grades regulares e irregulares para o período úmido, os valores de EMA e REQM apresentaram comportamentos semelhantes aos do período anual. As cokrigagens que envolveram a utilização da covariável altitude apresentaram erros menores dos valores preditos. Dessa maneira, ao se considerarem os períodos anual e úmido, a utilização de grade regular tendeu a permitir desempenho superior quanto aos parâmetros da regressão, tendo-se obtido os valores mais baixos de $\beta_{0}$ e mais elevados de $\beta_{1}$. Estes dois coeficientes, obtidos da regressão linear entre os valores observados e os preditos por krigagem e cokrigagem, fornecem a qualidade do ajuste dos modelos matemáticos aos semivariogramas (Carvalho et al., 2009). Indicativos de melhor desempenho na interpolação geoestatística, por meio dos coeficientes $\beta_{0}$ e $\beta_{1}$, foram encontrados também por Soares et al. (2008) e Carvalho et al. (2009).

Por meio da análise dos resultados de validação para a estação seca, nota-se que, no conjunto, a cokrigagem com altitude e distância do mar apresentou melhor desempenho na predição espacial, em relação à krigagem e cokrigagem com altitude. Diferentemente do observado para os períodos anual e úmido, a covariável distância do mar mostrou-se eficaz para predição da precipitação nesse período, se associada à altitude. Este resultado pode estar relacionado às precipitações orográficas que, no caso do período seco para o Espírito Santo, parece ser mais eficientemente predita quando se consideram simultaneamente a altitude e distancia do mar. Conforme os coeficientes de correlação verificados, quanto menor a altitude e maior a proximidade do mar, maior a precipitação nesse período. Essa influência da distância do mar na melhoria da interpolação está relacionada à boa correlação entre esta variável e a precipitação nesse período. No entanto, esperava-se melhor desempenho da cokrigagem com a distância do mar, se considerado que o maior coeficiente de correlação entre as covariáveis e a precipitação pluvial foi verificado para a distância do mar e a precipitação do período seco.

Os valores de EMA para o período seco foram superiores aos observados para os períodos anual e úmido (Tabela 3). Comportamento semelhante e valores compatíveis de EMA foram encontrados por Silva et al. (2011), com a utilização da krigagem ordinária para interpolação de dados de precipitação mensal no Estado do Espírito Santo. Neste caso, maiores erros de predição podem evidenciar a maior variabilidade espacial da precipitação da estação seca, que apresenta maior coeficiente de variação (Tabela 1). Nesse sentido, Viola et al. (2010) concluíram que a maior variabilidade dos índices pluviométricos na época seca, para o Estado de Minas Gerais, dificultou a reconstituição da continuidade espacial pelos interpoladores e produziu maiores erros de predição. A alta variabilidade espacial da época seca origina-se da grande amplitude de precipitação, nos diferentes postos pluviométricos e está relacionada a vários fatores (Mello \& Silva, 2009), um dos quais é a própria magnitude dos valores de precipitação nesse período, pois, como são baixos, uma pequena alteração pode representar variabilidade significativa e impactar os valores do coeficiente de variação. Conforme verificado por Viola et al. (2010) para o Estado de Minas Gerais, a ocorrência de frentes frias é um do fatores que conduz à maior variabilidade das chuvas, que são mais reduzidas no norte do Estado. No caso do Espírito Santo, além desse fator, a alta variabilidade na época seca pode ser influenciada pela ocorrência das precipitações orográficas.

Embora a avaliação das grades regulares e irregulares tenha sido para as covariáveis, os resultados observados são em geral consistentes com a teoria geoestatística. Na krigagem, para um mesmo tamanho amostral, o desempenho preditivo é afetado pelo plano de amostragem (Li \& Heap, 2011) e, de modo geral, as grades regulares resultam em variância da predição minimizada, pois fornecem melhores estimativas em comparação às amostragens aleatórias em grades 
irregulares (Hengl, 2007). Entretanto, o padrão de amostragem regular ou irregular pode, em alguns casos, não resultar em diferenças significativas (Li \& Heap, 2011). Assim, diferentemente das interpolações nos períodos úmido e anual, com base nos erros de predição, o uso de grades regulares para as covariáveis na estação seca produziu estimativas equiparáveis ao de grades irregulares (Tabela 3 ).

As pequenas diferenças dos valores de EM e REQM, nas comparações entre krigagem e cokrigagem e entre grade regular e irregular, são reforçadas pela análise estatística dos valores dos índices kappa (Tabela 4). No período úmido, a quase totalidade das comparações apresentou diferença significativa, mas, em três situações, não houve diferença significativa entre os mapas gerados, que são: na comparação entre krigagem versus cokrigagem com distância do mar em grade regular e irregular; cokrigagem com altitude versus cokrigagem com altitude e distância do mar, ambas em grade regular; cokrigagem com distância do mar em grade regular versus cokrigagem com distância do mar e grade irregular. Estas situações correspondem aos casos em que as diferenças dos erros médios são mais baixas (Tabela 3), o que indica que, apenas nesses casos, os mapas não são estatisticamente diferentes pelo teste $\mathrm{Z}$, a $5 \%$ de probabilidade. No período seco, o mesmo fato ocorreu em três situações: na comparação entre

Tabela 4. Matriz de significância entre índices kappa, variâncias do kappa $\left(\sigma^{2}\right)$ dos diferentes mapas de precipitação nos períodos úmido, seco e anual, obtidos por cokrigagem, ao se considerar como referência os mapas gerados por meio do interpolador inverso de uma potência da distância.

\begin{tabular}{|c|c|c|c|c|c|c|c|c|}
\hline \multirow[t]{2}{*}{ Tipo de grade } & \multirow[t]{2}{*}{ Método } & \multirow[b]{2}{*}{$\mathrm{KO}$} & \multicolumn{3}{|c|}{ Grade regular } & \multicolumn{3}{|c|}{ Grade irregular } \\
\hline & & & CKA & CKD & CKAD & CKA & CKD & CKAD \\
\hline & \multicolumn{8}{|c|}{ Período úmido } \\
\hline Indice kappa & - & 0,66 & 0,54 & 0,66 & 0,54 & 0,59 & 0,66 & 0,50 \\
\hline \multirow[t]{3}{*}{$\sigma^{2}\left(\mathrm{x} 10^{-6}\right)$} & - & 4,8608 & 5,5745 & 4,8628 & 5,5934 & 5,3508 & 4,8709 & 5,7380 \\
\hline & $\mathrm{KO}$ & 0,00 & $-36,12 *$ & $-0,04$ & $-37,22 *$ & $-23,10^{*}$ & $-0,39$ & $-50,33 *$ \\
\hline & CKA & & 0,00 & $36,08^{*}$ & $-1,10$ & $12,97^{*}$ & $35,72 *$ & $-14,03^{*}$ \\
\hline \multirow[t]{3}{*}{ Grade regular } & CKD & & & 0,00 & $-37,19^{*}$ & $-23,06^{*}$ & $-0,36$ & $-50,29^{*}$ \\
\hline & CKAD & & & & 0,00 & $14,07^{*}$ & $36,83^{*}$ & $-12,92 *$ \\
\hline & CKA & & & & & 0,00 & $22,70^{*}$ & $-27,05^{*}$ \\
\hline \multirow[t]{3}{*}{ Grade irregular } & CKD & & & & & & 0,00 & $-49,93 *$ \\
\hline & CKAD & & & & & & & 0,00 \\
\hline & \multicolumn{8}{|c|}{ Período seco } \\
\hline Índice kappa & - & 0,62 & 0,66 & 0,62 & 0,61 & 0,65 & 0,61 & 0,59 \\
\hline \multirow[t]{3}{*}{$\sigma^{2}\left(\mathrm{x} 10^{-6}\right)$} & - & 5,1042 & 4,8371 & 5,0636 & 5,1699 & 4,8724 & 5,1501 & 5,2715 \\
\hline & $\mathrm{KO}$ & 0,00 & $12,16^{*}$ & 1,81 & $-3,76^{*}$ & $10,50^{*}$ & $-2,32 *$ & $-9,67 *$ \\
\hline & CKA & & 0,00 & $-10,35^{*}$ & $-15,93 *$ & $-1,66$ & $-14,48^{*}$ & $-21,86^{*}$ \\
\hline \multirow[t]{3}{*}{ Grade regular } & CKD & & & 0,00 & $-5,57 *$ & $8,70^{*}$ & $-4,13^{*}$ & $-11,49^{*}$ \\
\hline & CKAD & & & & 0,00 & $14,28^{*}$ & 1,44 & $-5,91 *$ \\
\hline & CKA & & & & & 0,00 & $-12,83^{*}$ & $-20,20 *$ \\
\hline \multirow[t]{3}{*}{ Grade irregular } & CKD & & & & & & 0,00 & $-7,35^{*}$ \\
\hline & CKAD & & & & & & & 0,00 \\
\hline & \multicolumn{8}{|c|}{ Período anual } \\
\hline Índice kappa & - & 0,60 & 0,52 & 0,57 & 0,51 & 0,55 & 0,57 & 0,54 \\
\hline \multirow[t]{3}{*}{$\sigma^{2}\left(\times 10^{-6}\right)$} & - & 5,1273 & 5,4680 & 5,3139 & 5,4987 & 5,4204 & 5,3173 & 5,4384 \\
\hline & $\mathrm{KO}$ & 0,00 & $-25,56^{*}$ & $-11,74^{*}$ & $-29,27^{*}$ & $-17,70^{*}$ & $-11,56^{*}$ & $-20,15^{*}$ \\
\hline & CKA & & 0,00 & $13,79^{*}$ & $-3,68^{*}$ & $7,80^{*}$ & $13,96^{*}$ & $5,37 *$ \\
\hline \multirow[t]{3}{*}{ Grade regular } & CKD & & & 0,00 & $-17,48^{*}$ & $-5,97 *$ & 0,18 & $-8,40^{*}$ \\
\hline & CKAD & & & & 0,00 & $11,48^{*}$ & $17,65^{*}$ & $9,05^{*}$ \\
\hline & CKA & & & & & 0,00 & $6,14^{*}$ & $-2,43^{*}$ \\
\hline \multirow[t]{2}{*}{ Grade irregular } & CKD & & & & & & 0,00 & $-8,58^{*}$ \\
\hline & CKAD & & & & & & & 0,00 \\
\hline
\end{tabular}

KO, krigagem ordinária; CKA, cokrigagem com altitude; CKD, cokrigagem com distância do mar; CKAD, cokrigagem com altitude e distância do mar. *Significativo a $5 \%$ de probabilidade, pelo teste Z. Período seco (maio a setembro); e período úmido (outubro a abril). 
krigagem versus cokrigagem com distância do mar em grade regular; cokrigagem com altitude em grade regular versus cokrigagem com altitude em grade irregular; cokrigagem com altitude e distância do mar em grade regular versus cokrigagem com distância do mar em grade irregular. No caso da precipitação anual, todos os mapas comparados apresentaram diferenças entre si pelo teste $Z$, o que constitui um indicativo de que as pequenas diferenças de EMA e REQM (Tabela 3) foram suficientes para revelar a superioridade da cokrigagem em relação à krigagem e das grades regulares em relação às irregulares.

Assim, a cokrigagem proporcionou uma ligeira superioridade na predição da precipitação para os três períodos avaliados. Segundo Isaaks \& Srivastava (1989), é possível uma redução da variância do erro de estimação com a cokrigagem quando há correlação entre elas e o semivariograma cruzado mostra dependência entre as variáveis. No entanto, os baixos coeficientes de correlação, verificados entre as variáveis e as covariáveis utilizadas, podem ter limitado um maior ganho no desempenho da cokrigagem. Ocorre influência maior da variável secundária quando a correlação entre esta e a variável primária é mais alta. Quando a correlação é baixa, a variável primária é retida como informação mais confiável no processo de interpolação por cokrigagem (Rocha et al., 2012).

Os valores de precipitação média anual variam predominantemente de forma crescente, no sentido norte-sul do Estado, com os maiores valores na região serrana sul (Figura 3C). Esta distribuição espacial da precipitação está de acordo com Silva \& Lima (2011), que verificaram que os menores índices de precipitação ocorrem na região norte, oeste e litoral sul do Estado do Espírito Santo; e com os maiores índices, em parte, no litoral sul e região serrana sul.

Nos mapas de erro-padrão da predição, que medem a confiança dos valores interpolados, constata-se que as localizações próximas aos postos pluviométricos geralmente possuem erros-padrão menores do que as mais distantes (Figura 4). Conforme Mello Junior et al. (2006), esse comportamento é característico da variância de krigagem. Maior variância representa, também, maior incerteza para a predição, o que indica a necessidade de

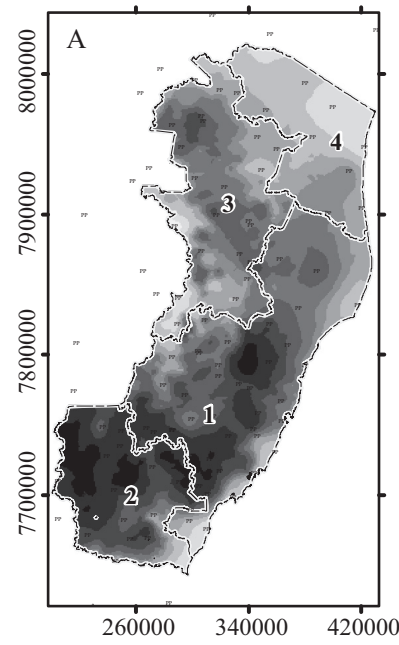

Precipitação (mm)
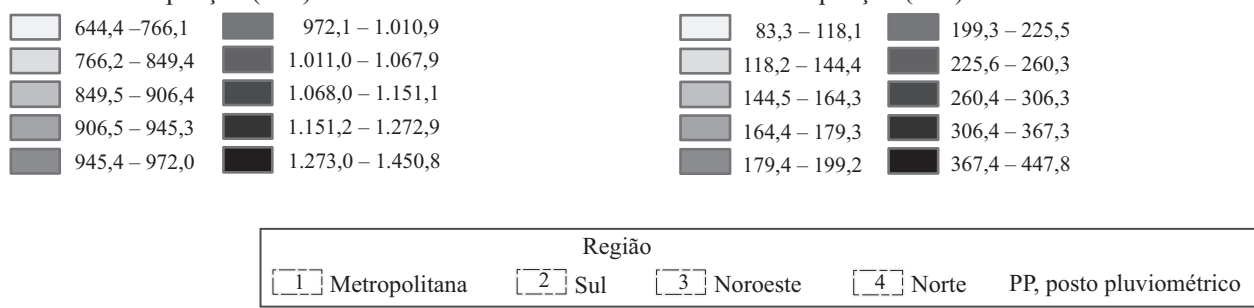

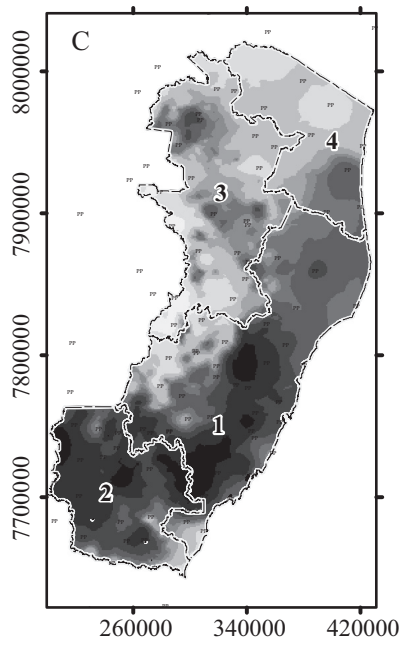

Precipitação (mm)
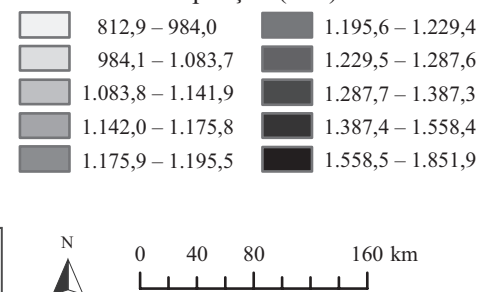

Figura 3. Mapas de precipitação dos períodos úmido (A), seco (B) e anual (C), estimados por cokrigagem com altitude, cokrigagem com altitude mais distância do mar, e cokrigagem com altitude, respectivamente. 

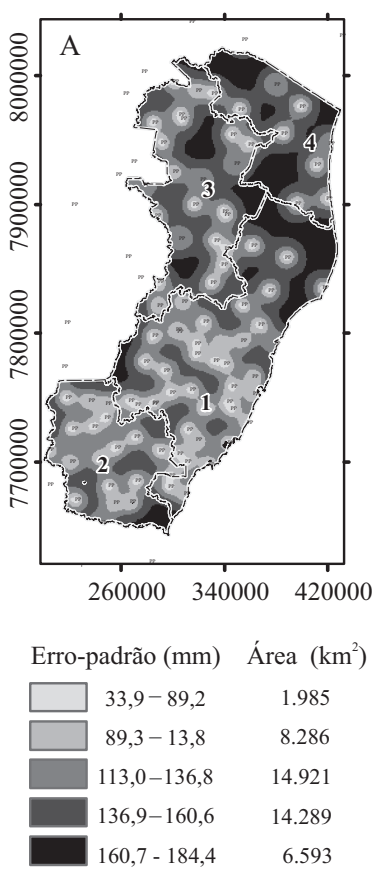

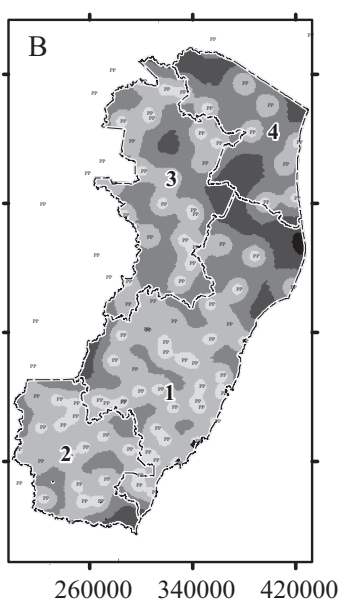

Erro-padrão (mm) Área $\left(\mathrm{km}^{2}\right)$

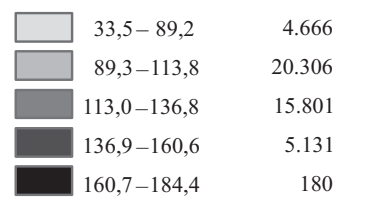

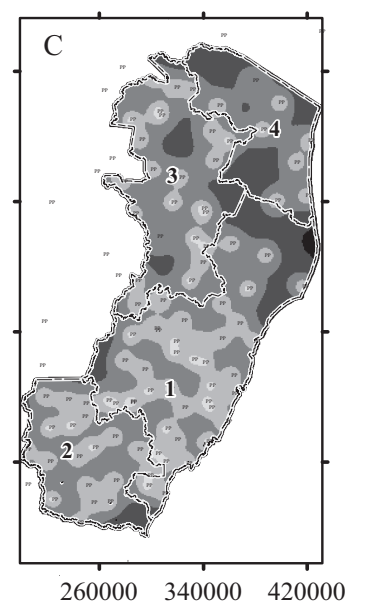

Erro-padrão (mm) Área $\left(\mathrm{km}^{2}\right)$

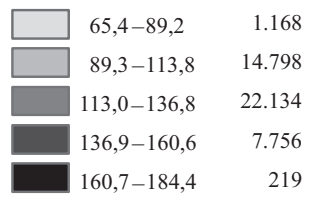

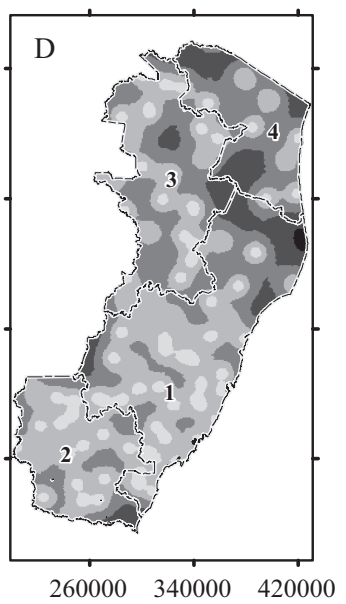

Erro-padrão (mm) Área $\left(\mathrm{km}^{2}\right)$

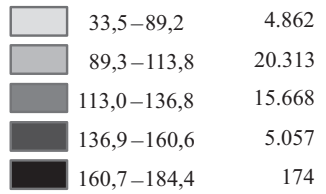

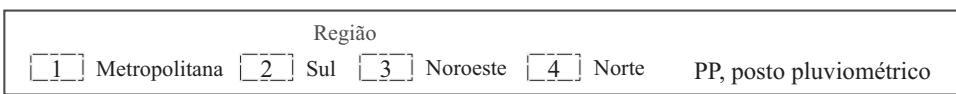

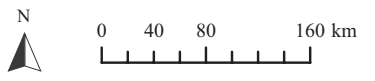

Figura 4. Mapas de erro-padrão da predição de precipitação anual (mm), obtidos por krigagem (A), cokrigagem com altitude (B), distância do mar (C) e altitude e distância do mar (D).

um número maior de postos pluviométricos na região norte do Estado, caso o objetivo seja a redução de áreas com elevada incerteza. Além deste fato, de acordo com Webster \& Oliver (2007), para se obter uma estimativa confiável de variogramas isotrópicos, são necessários dados de pelo menos 144 pontos de amostragem e que, com cerca de 400 pontos, é possível a estimação com grande precisão.

Os maiores erros-padrão das predições referentes à precipitação média anual ocorreram geralmente em áreas situadas próximas às regiões nordeste e norte do Estado. Na cokrigagem com altitude, que obteve melhor desempenho na interpolação, conforme resultados da validação cruzada, a classe de erro-padrão com valores menores do que $89,2 \mathrm{~mm}$ ocupam $10,5 \%$ da área do Estado (Figura 4). Na krigagem ordinária, essa mesma classe ocupa um total de $4,3 \%$ da área. Numa comparação entre regiões, no norte do Estado, a ocorrência dessa classe foi de $0,5 \%$, enquanto na metropolitana alcançou 4,6\%. Nas áreas ao norte do Estado, os valores preditos de precipitação estão supostamente associados a maior nível de incerteza, que se relaciona com a baixa densidade de postos pluviométricos. Além disso, as áreas com maior incerteza da estimação foram reduzidas nos mapas de precipitação gerados por cokrigagem.

\section{Conclusões}

1. A cokrigagem com uso de grades regulares oferece maior precisão do que a krigagem ordinária, na interpolação da precipitação pluvial no Estado do Espírito Santo.

2. Autilização da altitude como covariável possibilita melhor desempenho da interpolação por cokrigagem, em comparação à covariável distância do mar.

\section{Agradecimentos}

Ao Instituto Nacional de Colonização e Reforma Agrária (Incra), pelo apoio financeiro; ao Instituto Capixaba de Pesquisa e Extensão Rural (Incaper), pela cessão de dados de precipitação pluvial.

Pesq. agropec. bras., Brasília, v.48, n.9, p.1179-1191, set. 2013 DOI: $10.1590 / \mathrm{S} 0100-204 X 2013000900001$ 


\section{Referências}

AGÊNCIA NACIONAL DE ÁGUAS. Hidroweb: sistemas de informações hidrológicas. Disponível em: <http://hidroweb.ana. gov.br/>. Acesso em: 18 out. 2011.

BERTONI J.C.; TUCCI, C.E.M. Precipitação. In: TUCCI, C.E.M. Hidrologia: ciência e aplicação. 4.ed. Porto Alegre: Ed. da UFRGS, 2007. p.177-241.

CAMARGO, E.C.G.; FUCKS, S.D.; CÂMARA, G. Análise espacial de superfícies. In: DRUCK, S.; CARVALHO, M.S.; CÂMARA, G.; MONTEIRO, A.M.V. (Ed.). Análise espacial de dados geográficos. Planaltina: Embrapa Cerrados, 2004. p.79-122.

CARVALHO, J.R.P. de; ASSAD, E.D. Análise espacial da precipitação pluviométrica no Estado de São Paulo: comparação de métodos de interpolação. Engenharia Agrícola, v.25, p.377-384, 2005. DOI: 10.1590/S0100-69162005000200011.

CARVALHO, J.R.P. de; ASSAD, E.D.; PINTO, H.S. Interpoladores geoestatísticos na análise da distribuição espacial da precipitação anual e de sua relação com altitude. Pesquisa Agropecuária Brasileira, v.47, p.1235-1242, 2012. DOI: 10.1590/ S0100-204X2012000900008.

CARVALHO, J.R.P. de; VIEIRA, S.R.; GREGO, C.R. Comparação de métodos para ajuste de modelos de semivariograma da precipitação pluvial anual. Revista Brasileira de Engenharia Agrícola e Ambiental, v.13, p.443-448, 2009. DOI: 10.1590/ S1415-43662009000400011.

CASTRO, F. da S. Zoneamento agroclimático para a cultura do pinus no Estado do Espírito Santo. 2008. 101p. Dissertação (Mestrado) - Universidade Federal do Espírito Santo, Alegre.

CONGALTON, R.G.; GREEN, K. Assessing the accuracy of remotely sensed data: principles and practices. $2^{\text {nd }}$ ed. Boca Raton: Taylor and Francis, 2009. 183p.

DIODATO, N.; CECCARELLI, M. Interpolation processes using multivariate geostatistics for mapping of climatological precipitation mean in the Sannio Mountains (Southern Italy). Earth Surface Processes and Landforms, v.30, p.259-268, 2005. DOI: 10.1002/esp.1126.

ENGLUND, E.; WEBER, D.; LEVIANT, N. The effects of sampling design parameters on block selection. Mathematical Geology, v.24, p.329-343, 1992. DOI: 10.1007/BF00893753.

GOOVAERTS, P. Geostatistical approaches for incorporating elevation into the spatial interpolation of rainfall. Journal of Hydrology, v.228, p.113-129, 2000. DOI: 10.1016/ S0022-1694(00)00144-X.

HENGL, T. A practical guide to geostatistical mapping of environmental variables. Luxembourg: Office for Official Publication of the European Communities, 2007. 146p.

INSTITUTO JONES DOS SANTOS NEVES. Limite entre macrorregiões do ES - Estado (Todos) - ano (2012). 2012. Disponível em: <http://www.ijsn.es.gov.br/Sitio/index. php? option $=$ com_content $\&$ view $=$ article $\& i d=3780 \&$ Itemid $=330>$. Acesso em: 13 fev. 2013.

ISAAKS, E.H.; SRIVASTAVA, R.M. An introduction to applied geostatistics. New York: Oxford University, 1989. 561p.
JOHANSSON, B.; CHEN, D.L. The influence of wind and topography on precipitation distribution in Sweden: statistical analysis and modeling. International Journal of Climatology, v.23, p.1523-1535, 2003. DOI: 10.1002/joc.951.

KRISHNA MURTHY, B.R.; ABBAIAH, G. Geostatistical analysis for estimation of mean rainfalls in Andhra Pradesh, India. International Journal of Geology, v.1, p.35-51, 2007.

LI, J.; HEAP, A.D. A review of comparative studies of spatial interpolation methods in environmental sciences: performance and impact factors. Ecological Informatics, v.6, p.228-241, 2011. DOI: 10.1016/j.ecoinf.2010.12.003.

MELLO, C.R. de; SILVA, A.M. da. Modelagem estatística da precipitação mensal e anual e no período seco para o Estado de Minas Gerais. Revista Brasileira de Engenharia Agrícola e Ambiental, v.13, p.68-74, 2009. DOI: 10.1590/ S1415-43662009000100010.

MELO JÚNIOR, J.C.F. de; SEDIYAMA, G.C.; FERREIRA, P.A.; LEAL, B.G.; MINUSI, R.B. Distribuição espacial da freqüência de chuvas na região hidrográfica do Atlântico, Leste de Minas Gerais. Revista Brasileira de Engenharia Agrícola e Ambiental, v.10, p.417-425, 2006. DOI: 10.1590/S141543662006000200024.

MORAL, F.J. Comparison of different geostatistical approaches to map climate variables: application to precipitation. International Journal of Climatology, v.30, p.620-631, 2010. DOI: 10.1002/ joc. 1913 .

PORTO JÚNIOR, R.; PIRES, B.P.; GOUVEIA, G.R.; BRANDÃO, V.S.; COUTINHO, N.M. Caracterização geológico-geotécnica do movimento de massa ocorrido entre as praias da Prainha e Grumari, no Município do Rio de Janeiro, RJ. Anuário do Instituto de Geociências, v.35, p.5-13, 2012.

RIBEIRO JÚNIOR, P.J.; DIGGLE, P.J. geoR: a package for geoestatistical analysis. R - News, v.1/2, p.15-18, 2001.

ROCHA, M.M.; YAMAMOTO, J.K.; WATANABE, J.; FONSECA, P.P. Studying the influence of a secondary variable in collocated cokriging estimates. Anais da Academia Brasileira de Ciências, v.84, p.335-346, 2012. DOI: 10.1590/ S0001-37652012005000017.

SILVA, K.R. da; CECÍLIO, R.A.; XAVIER, A.C.; PEZZOPANE, J.R.M.; GARCIA, G. de O. Interpolação espacial da precipitação no Estado do Espírito Santo. Floresta e Ambiente, v.18, p.417-427, 2011. DOI: 10.4322/floram.2011.061.

SILVA, S. de A.; LIMA, J.S. de S. Número de postos pluviométricos necessários para a estimativa da precipitação mensal no Estado do Espírito Santo, Brasil. Revista Brasileira de Meteorologia, v.26, p.555-560, 2011. DOI: 10.1590/S0102-77862011000400005.

SOARES, V.P.; ZANETI, L.Z.; SANTOS, N.T.; LEITE, H.G. Análise espacial da distribuição de cigarras (Quesada gigas Oliver) em povoamentos de paricá (Schizolobium amazonicum Huber ex Ducke) na região de Dom Eliseu, PA. Revista Árvore, v.32, p.251-258, 2008. DOI: 10.1590/S0100-67622008000200008.

VIOLA, M.R.; MELLO, C.R. de; PINTO, D.B.F.; MELLO, J.M. de; ÁVILA, L.F. Métodos de interpolação espacial para o mapeamento da precipitação pluvial. Revista Brasileira de 
Engenharia Agrícola e Ambiental, v.14, p.970-978, 2010. DOI: 10.1590/S1415-43662010000900009.

VIVIANI, E.; MANZATO, G.G. Geração de modelos digitais de superfície por meio de plataformas computacionais com estrutura vetorial e raster. Ciência e Engenharia, v.15, p.27-34, 2005.

WEBSTER, R.; OLIVER, M. Geostatistics for environmental scientists. Chichester: J. Wiley, 2007. 315p.

$\overline{\text { Recebido em } 14 \text { de abril de } 2013 \text { e aprovado em } 12 \text { de agosto de } 2013}$ 